\title{
The Swedish Version of the Electronic Health Literacy Scale: Prospective Psychometric Evaluation Study Including Thresholds Levels
}

Josefin Wångdahl ${ }^{1,2}, \mathrm{PhD}$; Maria Jaensson ${ }^{3}, \mathrm{PhD}$; Karuna Dahlberg ${ }^{3}$, PhD; Ulrica Nilsson ${ }^{2,4}, \mathrm{PhD}$

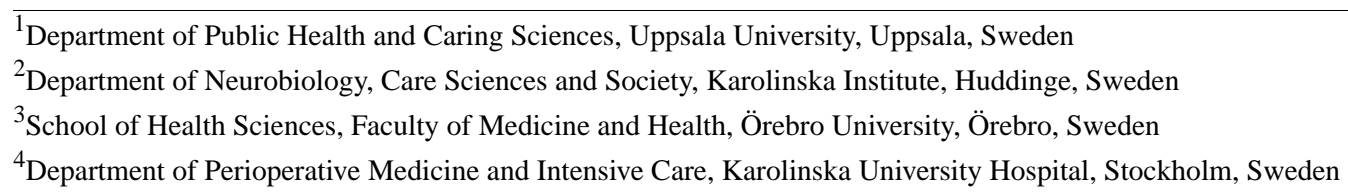

Corresponding Author:

Ulrica Nilsson, $\mathrm{PhD}$

Department of Neurobiology, Care Sciences and Society

Karolinska Institute

Alfred Nobels Allé 23

Huddinge

Sweden

Phone: 46852483822

Email: ulrica.nilsson@ki.se

\section{Abstract}

Background: To enhance the efficacy of information and communication, health care has increasingly turned to digitalization. Electronic health (eHealth) is an important factor that influences the use and receipt of benefits from Web-based health resources. Consequently, the concept of eHealth literacy has emerged, and in 2006 Norman and Skinner developed an 8-item self-report instrument to measure these skills: the eHealth Literacy Scale (eHEALS). However, the eHEALS has not been tested for reliability and validity in the general Swedish population and no threshold values have been established.

Objective: The aim of this study was to translate and adapt eHEALS into a Swedish version; evaluate convergent validity and psychometric properties; and determine threshold levels for inadequate, problematic, and sufficient eHealth literacy.

Methods: Prospective psychometric evaluation study included 323 participants equally distributed between sexes with a mean age of 49 years recruited from 12 different arenas.

Results: There were some difficulties translating the English concept health resources. This resulted in this concept being translated as health information (ie, Hälsoinformation in Swedish). The eHEALS total score was 29.3 (SD 6.2), Cronbach alpha .94 , Spearman-Brown coefficient .96 , and response rate $94.6 \%$. All a priori hypotheses were confirmed, supporting convergent validity. The test-retest reliability indicated an almost perfect agreement, $.86(P<.001)$. An exploratory factor analysis found one component explaining $64 \%$ of the total variance. No floor or ceiling effect was noted. Thresholds levels were set at 8 to $20=$ inadequate, 21 to $26=$ problematic, and 27 to $40=$ sufficient, and there were no significant differences in distribution of the three levels between the Swedish version of eHEALS and the HLS-EU-Q16.

Conclusions: The Swedish version of eHEALS was assessed as being unidimensional with high internal consistency of the instrument, making the reliability adequate. Adapted threshold levels for inadequate, problematic, and sufficient levels of eHealth literacy seem to be relevant. However, there are some linguistic issues relating to the concept of health resources.

(JMIR Mhealth Uhealth 2020;8(2):e16316) doi: $\underline{10.2196 / 16316}$

\section{KEYWORDS}

eHealth; literacy; internet; psychometrics 


\section{Introduction}

Globally, the internet is an important resource for health-related information and health services, which requires a range of digital skills among users and also new ways of describing and evaluating users' digital capabilities and experience in this rapidly changing health context [1]. The use of the internet in Sweden has steadily increased in recent years, and currently about $95 \%$ of all households have internet access. Internet access has increased the most in the elderly population, and in people aged 76 years and older, $87 \%$ have internet access at home. Of those, $49 \%$ use the internet to seek health-related information, compared with $96 \%$ of persons aged 26 to 45 years, $90 \%$ to $95 \%$ of persons aged 46 to 65 years, and $76 \%$ of persons aged 66 to 75 years [2]. In the present health care system, people are expected to participate and be engaged in their own care; they must be able to understand health instructions regarding how to manage their care (ie, health literacy) [3-5]. Traditional health literacy refers to an individual's ability to use printed information. However, with the increasing digitalization of information and services, the modern health care system must be aware of the health literacy levels of its patients in cyber space in order to maximize the benefits of electronic health (eHealth) technologies, challenging for both patients and health care staff [6].

The internet is significantly impacting health and health care, and it has the potential to advance health care delivery and support decision-making [1,7]. Thus, internet-enabled health care is a strategic priority globally. EHealth is an important factor that influences the use and receipt of benefits from Web-based health resources $[1,8]$. Consequently, the concept of eHealth literacy has emerged $[1,9,10]$ and has been described as "the ability to seek, find, understand, and appraise health information from electronic sources and apply the knowledge gained to addressing or solving a health problem" [10].

Because eHealth literacy is a more recent construct than health literacy, it is hard to find studies that have been published regarding its association with health outcomes [11]. However, limited health literacy has been found to affect a person's quality of care, resulting in lower satisfaction with care and a lower understanding of their medical situation [12,13]. This increases, for example, the probability of an adverse medication reaction because of misunderstanding the instructions $[12,14]$. Health literacy is also associated with the extent to which people benefit from health examinations [15], the quality of their postoperative recovery [16], and even mortality [11].

In a systematic review of questionnaires measuring eHealth literacy, 8 questionnaires were identified. It is noteworthy that the eHealth Literacy Scale (eHEALS) questionnaire was used in 45 of the 53 included articles [17]. eHEALS was developed in 2006 by Norman and Skinner [10] and aims to measure a broad range of literacy skills, which could make it useful in assessing the effects of strategies for delivering online information and applications. eHEALS is an 8-item instrument with each item scored on a 5-point Likert scale with response options ranging from strongly agree to strongly disagree. Total scores on the eHEALS range from 8 to 40, with higher scores representing higher self-perceived eHealth literacy [10].

The eHEALS is available in a range of languages [9,10,18-23], and the English version has been successfully administered via telephone [24]. Psychometric testing of eHEALS indicates that it is a reliable and valid instrument [10,23,25-27] but also that its validity requires further investigation [9]. However, there are no threshold levels for eHEALS, and eHEALS has not been tested for validity in the general Swedish population. Thus, the aim of our research was to translate and adapt the eHEALS into a Swedish version; evaluate convergent validity and psychometric properties; and determine threshold levels for inadequate, problematic, and sufficient eHealth literacy.

\section{Methods}

\section{Study Design and Participants}

This prospective psychometric evaluation study was conducted in three phases: translation, content validity testing, and psychometric evaluation. Data collection for phases 1 and 2 was completed from September 2018 to January 2019 and for phase 3 from February 2019 to May 2019 [28]. The project was approved by the Regional Ethical Review Board in Stockholm, Sweden, (no 2019/5:1) and follows the principles outlined in the 1964 Helsinki Declaration and its subsequent amendments. Participants received written and verbal information about the study, including its purpose and procedures, the voluntary nature of participation, and their option to withdraw at any time. By answering the questionnaire, participants consented to taking part in the study. Participants were also guaranteed confidentiality and secure data storage.

\section{Phase 1: Translation}

Permission to translate and use the eHEALS [10] was obtained from the creator of the instrument, Cameron D Norman, $\mathrm{PhD}$. After permission was granted, one professional translator with Swedish as a native language translated the original English version of eHEALS into Swedish (ie, the Swedish version of eHEALS [Sw-eHEALS]). The translator was instructed to use plain language and that the translation should be comprehensible to a 12-year-old child. This means that items should be short and simple and should not contain difficult words or jargon [29]. Two of the researchers (JW and UN) compared Sw-eHEALS with the original English version by examining how well it fit into the Swedish context and checking it for plain language. The researchers found that the Swedish version required some minor contextual changes and changes into simpler language in order to make it easier to understand the content. The translator stated that translating the English concept of health resources into Swedish was problematic because the Swedish concept of Hälsoresurser does not have the same meaning and the word is not commonly used in Swedish. The creator was contacted to discuss this, and he stated that there have been similar problems with the concept when translating it into other languages. Based on discussions with Dr Norman and also with four bilingual native English and Swedish speakers, it was decided to translate health resources as Hälsoinformation (ie, health information). 
An expert panel including seven Swedish speakers was recruited to examine the quality of the translation [30]. The panel included two teachers of Swedish for people with a different mother tongue, two development managers with expertise in communication in health care, and three researchers in medicine, caring sciences, and health literacy. The experts were asked to comment on spelling, grammar, and whether they thought the translation had been written in plain language. After reviewing the experts' feedback, the two researchers made some linguistic modifications and the Sw-eHEALS was then backtranslated by another native English-speaking translator who was blinded to the original eHEALS version. The backtranslated version and the original English eHEALS version were then compared by the translators and the two researchers. The two versions were found to match in terms of purpose and content.

\section{Phase 2: Face Validity}

In order to evaluate the face validity $[29,31]$ of the Sw-eHEALS, interviews were conducted with six participants recruited purposively and through snowball sampling [32] by two of the researchers (JW and UN) and one research assistant. A mix of ages, sexes, and educational levels was sought (see demographic characteristics of the participants in Table 1). Participants received verbal and written information about the face validity test and the main study and were instructed to think aloud during completion of the Sw-eHEAL and highlight any problematic points. They were also asked to reflect on why they selected specific responses.

Participants found the items easy to understand and answer and their verbal answers agreed with their marked answers in the Sw-eHEALS. There were no signs of misunderstandings. However, the concept of health information was interpreted slightly differently, even though the concept is broad. Some participants reported that the questions were quite similar and that they could be placed in a different order. They also reported that the Likert scale could include fewer or different alternatives. The face validity testing resulted in some minor changes in wording and confirmed the clarity and comprehensibility of Sw-eHEALS.

Table 1. Demographics of the content validity test group $(n=6)$.

\begin{tabular}{ll}
\hline Variable & Value \\
\hline Gender & 3 \\
$\quad$ Male & 3 \\
$\quad$ Female & 50 \\
Age in years & $28-78$ \\
$\quad$ Mean & 1 \\
$\quad$ Range & 2 \\
Educational level & 3 \\
$7-9$ years & 3 \\
10-12 years & 6 \\
More than 12 years & 3 \\
Country of birth, Sweden & 6 \\
\hline
\end{tabular}

\section{Phase 3: Psychometric Evaluation}

\section{Participants and Settings}

A study population comprising 300 participants was considered to be appropriate given that the general rule of thumb for factor analysis is 300 cases [33]. The inclusion criteria for participation was being an adult (aged 18 years and older), having Swedish as a native language, and being available on the day of the data collection. Participants were recruited from university courses, craft training, larger workplaces with academic and nonacademic staff, nongovernmental organizations serving elderly people, athletic clubs, and two choirs. A total of 12 arenas selected for diversity in age, sex, and level of education were visited by one of the researchers (JW).

\section{Study Questionnaires and Additional Questions}

The Sw-eHEALS, an additional questionniare, and general and demographics questions (age, biological sex, education level) were used. The HLS-EU-Q16 (Health Literacy Survey European Questionnaire, 16-item) aims to measure comprehensive health literacy (ie, perceived personal skills in finding, understanding, judging, and applying health information in order to maintain and improve health) [34]. The HLS-EU-Q16 was used to assess construct validity. HLS-EU-Q16 items were answered on a 4-point Likert scale ranging from very difficult to very easy. The total score of the index is summed to range from 0 to 16 , with higher scores representing higher self-perceived comprehensive levels of health literacy. Score points between 0 to 8 represents inadequate health literacy, 9 to 12 score points represents problematic comprehensive health literacy, and 13 to 16 score points represents sufficient comprehensive health literacy [34,35].

One question was asked about general self-perceived health: "How do you assess your overall health status?" Response options were very poor, poor, fair, good, and very good [15,36,37].

Two questions were asked about interest in using the internet. "How useful is the internet in helping you make decisions about your health?" Response options to this usability of the internet 
question were not useful at all, not useful, unsure, useful, and very useful. "How important is it for you to be able to access health resources on the internet?" Response options to this importance of the internet question were not important at all, not important, unsure, important, and very important [10].

One question was asked about the frequency of internet use: "How often do you use the internet?" Response options were almost every day, several days a week, around one day a week, less than one day a week, and almost never [9].

\section{Data Collection}

On the day of the data collection, one of the researchers (JW) visited the arenas and informed participants verbally and in writing about the project and the meaning of informed consent. Those participants who agreed to participate answered the questionnaire directly. In one of the arenas, however, the organization manager distributed the written information and questionnaire instead of the researcher because it was difficult for all the staff to attend a meeting.

For analysis test-retest reliability, some of the participants were invited to answer the questionnaire twice within one week. A sample size in the retest of 25 participants was considered appropriate [38]. However, in order to include participants of different ages, sex, and education levels, 35 persons were asked to participate in the test-retest. In order to compare answers from the test and retest on an individual level and to ensure anonymity, participants marked their questionnaires with a code comprising the first three letters of their mother's name and the year she was born.

\section{Psychometric Testing}

Psychometric testing was guided by the Consensus-Based Standards for the Selection of Health Measurement Instruments (COSMIN) [29,31,39].

\section{Feasibility}

Feasibility of the instrument was assessed by successful response rate and missing data from the questionnaires [39].

\section{Construct Validity}

Construct validity focuses on evaluating tests of the hypotheses and can be described as the degree to which scores of an instrument are consistent with a hypothesis [31]. Based on previous studies on health literacy showing positive associations between limited health literacy and high age [3,13,40,41], poor health $[15,16,40,42,43]$, and low education level [41,44,45], hypotheses regarding correlations between Sw-eHEALS and age, level of education, and self-perceived general health were used. Hypotheses regarding positive correlations between Sw-eHEALS and interest in and level of internet use [9] were also used. Furthermore, positive correlations were seen between Sw-eHEALS and the HLS-EU-Q16 total score and the four HLS-EU-Q16 items measuring aspects of health literacy in relation to the internet [28].

\section{Reliability}

\section{Internal Consistency}

Internal consistency describes the degree of interrelatedness among items [31]:

- Exploratory factor analysis with principal axis factoring was used to identify the underlying relationships between the items in Sw-eHEALS [29].

- Cronbach alpha was calculated for the sum score and each item to assess the average correlation of items within each scale.

- $\quad$ Split-half reliability was used to measure the correlation between random split segments and determine how much error in a test score is due to poor test construction [46].

\section{Test-Retest Reliability}

Test-retest reliability can be described as the extent to which scores for the same participants are the same in measurements repeated over time [31].

\section{Floor and Ceiling Effects}

Floor and ceiling effects (ie, number of respondents who achieved the lowest or highest possible scores [29]) were examined. Floor or ceiling effects were considered a problem if more than $15 \%$ of a study population achieved the lowest or highest possible score [29].

\section{Thresholds}

The Sw-eHEALS scores were categorized according to the threshold values for health literacy assessed by the HLS-EU-Q16 $[34,47]$ : inadequate $=0$ to 8 (represents $50 \%$ of the sum score for HLS-EU-Q16), problematic $=9$ to 12 (represents $25 \%$ of the sum score for HLS-EU-Q16), and sufficien $t=13$ to 16 (represents $25 \%$ of the sum score for HLS-EU-Q16). Adapted to Sw-eHEALS scores, the thresholds for eHealth literacy are inadequate $=8$ to 20 (represents $50 \%$ of the sum score for Sw-eHEALS), problematic $=21$ to 26 (represents $25 \%$ of the sum score for Sw-eHEALS), and sufficient $=27$ to 40 (represents $25 \%$ of the sum score for Sw-eHEALS).

\section{Statistical Analysis}

Data are presented as mean, standard deviation, number, percentage, or range. Spearman rank was used to analyze the correlation between the total mean scores on Sw-eHEALS and HLS-EU-Q16. Self-perceived health, level of education, and age were also used. A coefficient magnitude of $>.40$ was considered evidence of construct validity (ie, moderate to strong correlations) [39]. Internal consistency was measured using a Spearman-Brown coefficient with values between .70 to .90 considered acceptable $[48,49]$ and Cronbach alpha with a range of .70 to .95 considered acceptable $[29,46]$. Test-retest reliability was measured using the weighted kappa coefficient, with an accepted value of $\geq .70$ [29,50]. The Friedman test was used to analyze differences between Sw-eHEALS and HLS-EU-Q16 in terms of numbers of patients with inadequate, problematic, and sufficient health literacy. The chi-square test was used to analyze differences in sex, Student $t$ test was used to analyze differences in age, and the Wilcoxon signed-rank test was used to analyze differences in age, educational levels, general self-perceived health, and Sw-eHEALS levels between 
participants with the same levels of health literacy on both the Sw-eHEALS and HLS-EU-Q16 compared with those with different levels. All data were analyzed using SPSS Statistics version 24.0 for Windows (IBM Corp). Two-tailed $P$ values less than .05 were considered significant.

\section{Results}

\section{Feasibility}

A total of 368 persons were invited to participate, and 348 answered the study questionnaires, giving a response rate of 94.6\%; 24 questionnaires were incomplete and were excluded, resulting in a total of 323 valid questionnaires included in the analysis (Figure 1). There were no statistically significant differences regarding sex, age, or highest education level

Figure 1. Flowchart of the data collection.

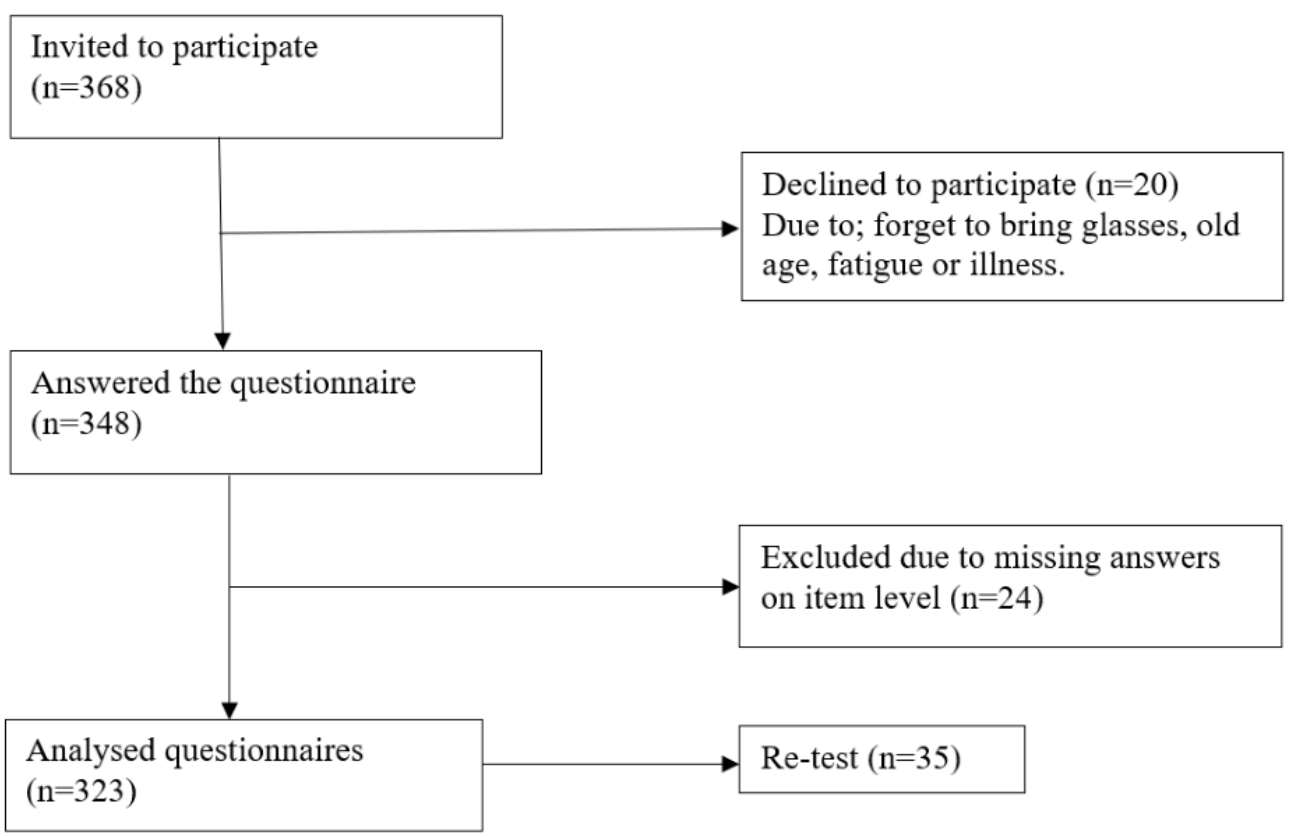

between the included participants versus those who declined to participate. Also, no pattern of structural problems in terms of difficulties in responding to certain items was found.

Sex was equally distributed, and the mean age was 49.2 (SD $21.5)$ years ranging from 19 to 94 years. Of the total, $90.4 \%$ (292/323) had at least 10 years' education, and 85.8\% (277/323) perceived their own general health as being good or very good. The majority $(231 / 323,71.5 \%)$ had sufficient comprehensive health literacy (HLS-EU-Q16), and the mean sum score of Sw-eHEALS was 29.3. Most participants reported that they used the internet almost every day $(284 / 323,87.9 \%)$, that they thought the internet was useful or very useful $(243 / 323,75.2 \%)$, and that the internet was important or very important $(250 / 323$, 77.4\%; Table 2). 
Table 2. Demographics of the respondents with a valid eHEALS sum score $(n=323)$ and the test-retest group ( $\mathrm{n}=35)$.

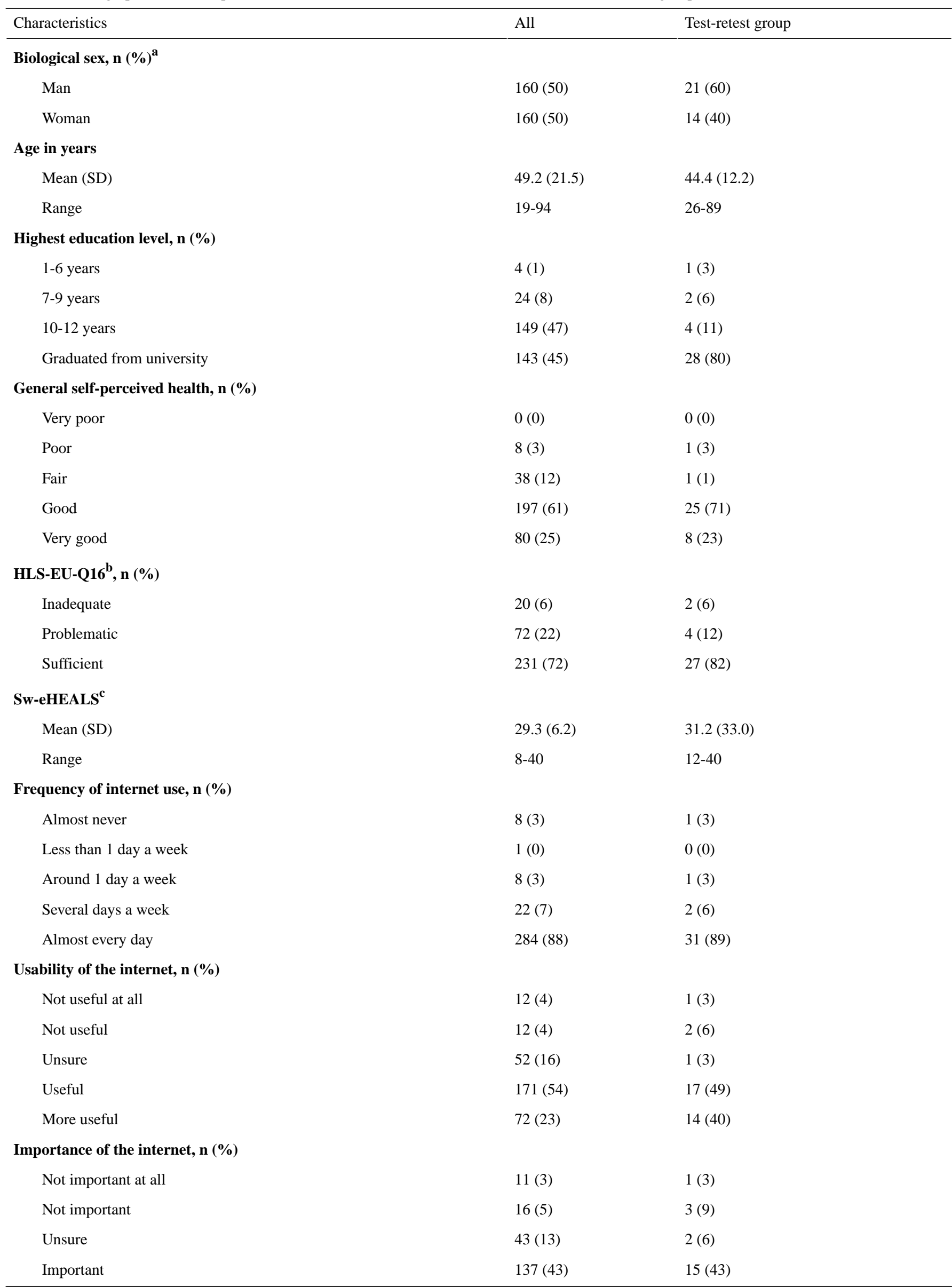




\begin{tabular}{cll}
\hline Characteristics & All & Test-retest group \\
\hline Very important & $113(35)$ & $14(40)$ \\
\hline
\end{tabular}

${ }^{\mathrm{a}}$ Missing $\mathrm{n}=3$.

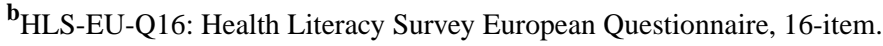

${ }^{\mathbf{c}}$ Sw-eHEALS: eHealth Literacy Scale.

\section{Construct Validity}

The Sw-eHEALS sum score was weak and negatively correlated with age and weak and positively correlated with education level, self-perceived health, frequency of using the internet, and

two items in the HLS-EU-Q16. Moderate positive correlations were found with perceptions of the internet as being useful and important, the HLS-EU-Q16 sum score, and two items on the HLS-EU-Q16 (Table 3).

Table 3. Spearman rho correlations between the Sw-eHEALS sum score and demographic characteristics, questions, and questionnaires.

\begin{tabular}{|c|c|c|}
\hline Variable & Value & $P$ value \\
\hline Age & -0.30 & $<.01$ \\
\hline Education level & 0.23 & $<.05$ \\
\hline Self-perceived health & 0.19 & $<.01$ \\
\hline Usability of the internet & 0.57 & $<.05$ \\
\hline Importance of the internet & 0.47 & $<.05$ \\
\hline Frequency of internet use & 0.36 & $<.05$ \\
\hline HLS-EU-Q16 ${ }^{\mathrm{a}}$ sum score & 0.47 & $<.05$ \\
\hline HLS-EU-Q16 item: Finding information about the treatment of illnesses that concern you & 0.51 & $<.05$ \\
\hline HLS-EU-Q16 item: Assessing whether information on health risks in the media is reliable & 0.49 & $<.05$ \\
\hline HLS-EU-Q16 item: Deciding on how you can protect yourself from illness based on information in the media & 0.37 & $<.05$ \\
\hline HLS-EU-Q16 item: Understanding information in the media about how to get healthier & 0.38 & $<.05$ \\
\hline
\end{tabular}

${ }^{\mathrm{a}}$ HLS-EU-Q16: Health Literacy Survey European Questionnaire, 16-item.

\section{Reliability}

Factor analysis showed that the Kayser-Meyer-Olkin measure of sampling adequacy for the analysis was good $(92, P<.001)$. The eigenvalue was 5.5 and explained $69 \%$ of the total variance, also reflected in the scree plot, which supported a unidimensional scale. All items loaded high ranging from .73 to .86. Cronbach alpha for the sum score of Sw-eHEALS was .94 and ranged from .92 to .93 for the individual items. The Spearman-Brown coefficient for the sum score of Sw-eHEALS was .96. Weighted Cohen kappa coefficient was acceptable for the sum score $(.86, P<.001)$ and ranged from .64 to $.79(P<.001)$ for the individual items (Table 4). 
Table 4. Reliability testing: exploratory factor analysis, Cronbach alpha, Spearman-Brown coefficient, and weighted quadratic Cohen kappa for the Swedish version of the eHealth Literacy Scale sum score or individual items.

\begin{tabular}{|c|c|c|c|c|}
\hline Variable & $\begin{array}{l}\text { Exploratory factor } \\
\text { analysis }\end{array}$ & Cronbach alpha & $\begin{array}{l}\text { Spearman-Brown } \\
\text { coefficient }\end{array}$ & $\begin{array}{l}\text { Weighted quadratic } \\
\text { Cohen kappa }\end{array}$ \\
\hline Sw-eHEALS ${ }^{\mathrm{a}}$ total score & - & .94 & .96 & .86 \\
\hline $\begin{array}{l}\text { Item 1: I know what health resources are available on the inter- } \\
\text { net }\end{array}$ & .73 & .93 & - & .64 \\
\hline $\begin{array}{l}\text { Item 2: I know where to find helpful health information on the } \\
\text { internet }\end{array}$ & .83 & .93 & - & .71 \\
\hline $\begin{array}{l}\text { Item 3: I know what health information is available on the inter- } \\
\text { net }\end{array}$ & .86 & .92 & - & .70 \\
\hline $\begin{array}{l}\text { Item 4: I know how to find helpful health information }{ }^{\mathrm{b}} \text { on the } \\
\text { internet }\end{array}$ & .85 & .92 & - & .79 \\
\hline $\begin{array}{l}\text { Item 5: I know how to use the health information }{ }^{\mathrm{b}} \text { I find on the } \\
\text { internet to help me }\end{array}$ & .82 & .93 & - & .72 \\
\hline $\begin{array}{l}\text { Item 6: I have the necessary skills to evaluate the health re- } \\
\text { sources I find on the internet }\end{array}$ & .74 & .93 & - & .75 \\
\hline $\begin{array}{l}\text { Item 7: I can distinguish between high- and low-quality health } \\
\text { information on the internet }\end{array}$ & .78 & .93 & - & .68 \\
\hline $\begin{array}{l}\text { Item 8: I feel confident in using information from the internet } \\
\text { to make health decisions }\end{array}$ & .79 & .93 & - & .72 \\
\hline
\end{tabular}

${ }^{\mathrm{a}} \mathrm{Sw}$-eHEALS: Swedish version of the eHealth Literacy Scale.

${ }^{b}$ Health information=health resources in the original version by Norman and Skinner [10]

\section{Test-Retest Reliability}

A total of 35 participants were included in the test-retest. The mean age was 44 years with a range of 26 to 89 years, $60 \%$ $(21 / 35)$ were male, $91 \%(32 / 35)$ had at least 10 years' education and $94 \%$ (33/35) perceived their own general health as being good or very good. The majority $(82 \%, 27 / 35)$ had sufficient comprehensive health literacy (HLS-EU-Q16), and the mean sum score of the Sw-eHEALS was 32.1. Most participants reported that they used the internet almost every day $(89 \%$, $31 / 35$ ), that they thought the internet was useful or very useful $(89 \%, 31 / 35)$, and that the internet was important or very important (83\%, 29/35; Table 2). The weighted quadratic Cohen kappa for the Sw-eHEALS total score was $.86(P<.001)$ and ranged from .70 to $.79(P<.001)$ for 6 items and .64 to .68 $(P<.001)$ for 2 items (Table 4$)$.

\section{Floor and Ceiling Effects}

A total of 2\% (7/323) of the participants had the lowest possible sum score and $4 \%(15 / 323)$ the highest possible sum score on the Sw-eHEALS.

\section{Thresholds}

The thresholds adapted for Sw-eHEALS resulted in $7.1 \%$ $(23 / 323)$ of participants with inadequate, $18.8 \%(61 / 323)$ with problematic, and $74.0 \%(239 / 323)$ with sufficient eHealth literacy. When comparing numbers of participants with inadequate, problematic, and sufficient health literacy between Sw-eHEALS and HLS-EU-Q16, there were no statistical differences $(P=.10)$, indicating that the thresholds determined for Sw-eHEALS seem to be relevant. Distribution between the three levels of eHealth literacy was similar for the HLS-EU-Q16, with $6.2 \%(20 / 323)$ of participants with inadequate, $22.3 \%$ (72/323) with problematic, and 71.5\% (231/323) with sufficient eHealth literacy (Table 2). When dichotomized into insufficient (inadequate + problematic) and sufficient eHealth literacy, there was a significantly greater proportion of participants who scored the same levels of health literacy on both questionnaires $(46+208=254 / 323,78.6 \%)$ compared with participants who had different scores $(42+27=69 / 323,21.4 \% ; P<.001$; Table 5). There were no significant differences in age, sex, educational level, or general self-perceived health between these two groups.

Table 5. Distribution of participants scoring insufficient and sufficient health literacy and eHealth literacy.

\begin{tabular}{lll}
\hline & Insufficient health literacy, $\mathrm{n}(\%)$ & Sufficient health literacy, $\mathrm{n}(\%)$ \\
\hline Insufficient electronic health literacy, $\mathrm{n}(\%)$ & $46(14.3)$ & $27(8.3)$ \\
Sufficient electronic health literacy, $\mathrm{n}(\%)$ & $42(13.1)$ & $208(64.3)$ \\
\hline
\end{tabular}




\section{Discussion}

\section{Principal Findings}

The results of this study support the intended use of Sw-eHEALS for measuring the self-reported eHealth literacy of Swedish persons. This paper shows that the process of translating an instrument from English into Swedish is not simple and quick. Capturing the culture and meaning of the words can be a challenge. Finding a suitable term for health resources in Swedish was problematic. Thus, several steps were taken that involved contacting the creator of the original instrument and also discussing the issue with experts and laymen. It is important that the content of the items remains the same as in the original. This is why we have described the translation process thoroughly. Although it is important that the content of the items remains the same as in the original version and reflects the true meaning of the construct, the wording or word order in the translated versions must be suitable for the target language and understandable by speakers with different levels of education and health literacy [30,51].

It has also been emphasized that translated items can assume different meanings and can affect the meanings perceived by the respondents. A lot of problems stem from the fact that the questions in the questionnaire or the wording of items in the instrument are culturally embedded. In other cases, structural differences mean that the exact equivalent objects or entities do not exist or that terms used to describe something in one country describe something else in another [52]. In this study, Sw-eHEALS was perceived as being easy to understand and answer, and no structural problems with specific items were found.

Our study found 1-factor structure (ie, unidimensionality) of the Sw-eHEALS, which is in line with previous studies, irrespective of using classical or modern test theory, as well as in different languages and populations $[9,18,20,22,53-56]$. The unidimensionality indicates that all the items measure a single underlying construct that is in line with what was originally proposed by the authors of the instrument [10]. However, a 2 -factor structure has been reported [26,57,58], divided into the constructs of knowledge about resources and evaluation of resources. A 3-factor structure has also been reported including the construct: awareness, skills, and evaluation [8,59]. The 1 -factor structure is important to Sw-eHEALS because this indicates it is appropriate to sum the item scores into a total score.

Internal consistency was assessed using Cronbach alpha and split-half reliability; both these coefficients were high, and the published recommendations for Cronbach alpha (ie, .70 to .95) were satisfied [29]. Other language versions of eHEALS have also reported high reliability with Cronbach alpha $\geq .88$ [18,20,22,53-55]. A high Cronbach alpha is usually found for questionnaires that contain a large number of items because Cronbach alpha is dependent on the number of items in a questionnaire [29]. The Sw-eHEALS includes 8 items.

The construct validity of the Sw-eHEALS was acceptable. Moderate positive correlations were found with the

HLS-EU-Q16, which is in line with Neter et al [58]. Moderate positive correlations were also found with perceptions of the internet as being useful and important for finding information about the treatment of illnesses that cause concern and assessing whether information about health risks in the media is reliable. Previous studies support the relationship between eHealth literacy, use of the internet $[9,18,20,53,60]$, mobile phone use [20], computer knowledge [53], and the amount of time spent online $[20,54]$. The findings have suggested that frequent internet users use the internet for health reasons and that this could result in a great level of self-reported eHealth literacy and that frequent internet users perceive that their ability to engage with and evaluate general internet resources is transferable to health-related content [8]. Furthermore, low eHealth literacy levels appear to be associated with poor skills using a personal computer, downloading files, and finding health information online and difficulties in receiving help from online sources [20].

The adapted threshold levels for inadequate, problematic, and sufficient levels of eHealth literacy were based on the levels for the HLS-EU-Q16 [35,47]. The threshold levels for Sw-eHEALS seem to be relevant, and it is important to establish these levels in order to identify those individuals and groups who suffer from inadequate and problematic eHealth literacy and are in need of support. To use a questionnaire without any thresholds or cutoff levels in research or in clinical practice is problematic because it is hard to evaluate what the values reflect (ie, insufficient or sufficient eHealth literacy). However, these suggested threshold levels for eHEALS have to be further evaluated in other populations and in other languages.

The test-retest reliability for the Sw-eHEALS sum score was .86 , indicating an almost perfect agreement [50], to be compared with the creators of eHEALS, $r=.68$ [10], and the Persian version, $r=.85$ [55], analyzed using Pearson correlation. In our study, the time period between repeated measurements was one week, compared with the Persian version, which had a 2 -week time period [55], and the original version, which had a 6-month follow-up [10]. If the time between the two tests is too long, respondents could have been exposed to things that changed their opinions, feelings, or attitudes about their behavior [51]. Terwee et al [29] believe that the time period between repeated administrations should be long enough to prevent recall but short enough to ensure that clinical changes have not occurred. Often, one or two weeks will be sufficient.

Floor and ceiling effects were acceptable; $2 \%$ of the participants scored the worst possible score (8), and $4 \%$ scored the best possible score (40). An acceptable floor and ceiling effect of eHEALS has been reported for the Italian version [18] and the Dutch version [9] in persons suffering from chronic disease [22] and in persons with moderate to high cardiovascular risk [26]. In an ideal situation, a questionnaire should be able to measure the entire spectrum of a phenomenon. If floor or ceiling effects are present, it is likely that extreme items will be missing at the lower or upper end of the scale. As a consequence, people with the lowest or highest possible score cannot be distinguished from each other, reducing reliability [29]. However, it has been reported that eHEALS does not seem to be able to detect small but clinically important changes in participants with mid to 
higher levels of eHealth literacy in a population suffering from moderate to high cardiovascular risk [26].

\section{Limitations}

This study has a number of limitations. One limitation is that the sample included may not be representative of the majority of Swedish speakers. However, the included participants were recruited from different arenas, including groups of different ages, sex, and levels of education. Second, eHEALS measures self-reported eHealth literacy, which is not the same as measuring the person's knowledge of eHealth. Self-reported eHealth literacy might be over- or underestimated depending on things like the person's level of self-efficacy. Therefore, further studies are needed to study the association between subjective and objective eHealth literacy. Another limitation was the use of a nonvalidated question to assess general self-perceived health. However, it has been claimed that self-perceived health is one of the internationally leading health indicators reflecting a person's subjective general perception of health [36]. It has also been argued that self-rated health is inclusive and dynamic in judging the trajectory of health and that it influences behaviors that subsequently affect health status and reflects resources that affect the ability to cope with health threats [37].

\section{Conclusion}

This study confirmed that Sw-eHEALS is a reliable and valid tool for assessing the perceived comfort and skills of Swedish speakers in using information technology for health (ie, eHealth literacy). However, there are some linguistic issues relating to the concept of health resources. The adapted threshold levels for inadequate, problematic, and sufficient levels of eHealth literacy seem to be relevant and important when conducting further studies, especially intervention studies.

\section{Acknowledgments}

This study is supported by Vetenskapsrådet (Swedish Research Council), grant number 2015-02273. A special thank you to the experts in the panel in phase 1 for their valuable input. We would also like to thank Anahita Amipour for helping with data collection in phase 2. Last, thank you to the participants of the study for their participation and help.

\section{Conflicts of Interest}

None declared.

\section{References}

1. Norgaard O, Furstrand D, Klokker L, Karnoe A, Batterham R, Kayser L. The e-health literacy framework: a conceptual framework for characterizing e-health users and their interaction with e-health systems. Knowl Manag Elearning Int J 2015 Jul;7(4):533-540. [doi: 10.34105/j.kmel.2015.07.035]

2. Davidsson P, Palm M, Mandre A. [The Swedes and the Internet 2018]. URL: https://svenskarnaochinternet.se/rapporter/ svenskarna-och-internet-2018/the-swedes-and-the-internet-2018-summary/ [accessed 2020-01-15]

3. Sørensen K, Pelikan JM, Röthlin F, Ganahl K, Slonska Z, Doyle G, et al. Health literacy in Europe: comparative results of the European health literacy survey (HLS-EU). Eur J Public Health 2015 Dec;25(6):1053-1058 [FREE Full text] [doi: 10.1093/eurpub/ckv043] [Medline: 25843827]

4. Koster ES, Schmidt A, Philbert D, van de Garde EMW, Bouvy ML. Health literacy of patients admitted for elective surgery. Z Gesundh Wiss 2017;25(2):181-186 [FREE Full text] [doi: 10.1007/s10389-016-0774-z] [Medline: 28357196]

5. Sørensen K, Van den Broucke S, Fullam J, Doyle G, Pelikan J, Slonska Z, et al. Health literacy and public health: a systematic review and integration of definitions and models. BMC Public Health 2012;12:80 [FREE Full text] [doi: 10.1186/1471-2458-12-80] [Medline: 22276600]

6. Tan SS, Goonawardene N. Internet health information seeking and the patient-physician relationship: a systematic review. J Med Internet Res 2017 Jan 19;19(1):e9 [FREE Full text] [doi: 10.2196/jmir.5729] [Medline: 28104579]

7. Kantor D, Bright JR, Burtchell J. Perspectives from the patient and the healthcare professional in multiple sclerosis: social media and patient education. Neurol Ther 2018 Jun;7(1):23-36 [FREE Full text] [doi: 10.1007/s40120-017-0087-3] [Medline: 29243028]

8. Hyde LL, Boyes AW, Mackenzie LJ, Leigh L, Oldmeadow C, Riveros C, et al. Electronic health literacy among magnetic resonance imaging and computed tomography medical imaging outpatients: cluster analysis. J Med Internet Res 2019 Aug 28;21(8):e13423 [FREE Full text] [doi: 10.2196/13423] [Medline: 31464188]

9. van der Vaart R, van Deursen AJ, Drossaert CH, Taal E, van Dijk JA, van de Laar MA. Does the eHealth Literacy Scale (eHEALS) measure what it intends to measure? Validation of a Dutch version of the eHEALS in two adult populations. J Med Internet Res 2011;13(4):e86 [FREE Full text] [doi: 10.2196/jmir.1840] [Medline: 22071338]

10. Norman CD, Skinner HA. eHEALS: the eHealth Literacy Scale. J Med Internet Res 2006 Nov;8(4):e27 [FREE Full text] [doi: 10.2196/jmir.8.4.e27] [Medline: 17213046]

11. Neter E, Brainin E. Association between health literacy, ehealth literacy, and health outcomes among patients with long-term conditions. Eur Psychol 2019 Jan 21;24(1):68-81 [FREE Full text] [doi: 10.1027/1016-9040/a000350]

12. Kirmayer LJ, Narasiah L, Munoz M, Rashid M, Ryder AG, Guzder J, Canadian Collaboration for Immigrant and Refugee Health (CCIRH). Common mental health problems in immigrants and refugees: general approach in primary care. CMAJ 2011 Sep 06;183(12):E959-E967 [FREE Full text] [doi: 10.1503/cmaj.090292] [Medline: 20603342] 
13. Berkman ND, Sheridan SL, Donahue KE, Halpern DJ, Crotty K. Low health literacy and health outcomes: an updated systematic review. Ann Intern Med 2011 Jul 19;155(2):97-107. [doi: 10.7326/0003-4819-155-2-201107190-00005] [Medline: $\underline{21768583}$

14. Sundquist J. Migration, equality and access to health care services. J Epidemiol Community Health 2001 Oct;55(10):691-692 [FREE Full text] [doi: 10.1136/jech.55.10.691] [Medline: 11553650 ]

15. Wångdahl J, Lytsy P, Mårtensson L, Westerling R. Health literacy and refugees' experiences of the health examination for asylum seekers: a Swedish cross-sectional study. BMC Public Health 2015 Nov 23;15:1162 [FREE Full text] [doi: 10.1186/s12889-015-2513-8] [Medline: 26596793]

16. Hälleberg Nyman M, Nilsson U, Dahlberg K, Jaensson M. Association between functional health literacy and postoperative recovery, health care contacts, and health-related quality of life among patients undergoing day surgery: secondary analysis of a randomized clinical trial. JAMA Surg 2018 Aug 01;153(8):738-745 [FREE Full text] [doi: 10.1001/jamasurg.2018.0672] [Medline: 29710226]

17. Karnoe A, Kayser L. How is eHealth literacy measured and what do the measurements tell us? A systematic review. Knowl Manag ELearn Int J 2015;7(4):576-600. [doi: 10.34105/j.kmel.2015.07.038]

18. Diviani N, Dima AL, Schulz PJ. A psychometric analysis of the Italian version of the ehealth literacy scale using item response and classical test theory methods. J Med Internet Res 2017 Apr 11;19(4):e114 [FREE Full text] [doi:

10.2196/jmir.6749] [Medline: 28400356]

19. Tomás C, Queirós P, Ferreira T. [Analysis of the psychometric properties of the Portuguese version of an eHealth literacy assessment tool]. Rev Enf Ref 2014 Jun 30;4(2):19-28. [doi: 10.12707/RIV14004]

20. Chang A, Schulz PJ. The measurements and an elaborated understanding of Chinese eHealth literacy (C-eHEALS) in chronic patients in China. Int J Environ Res Public Health 2018 Dec 23;15(7):1553. [doi: 10.3390/ijerph15071553] [Medline: 30041420]

21. Mitsutake S, Shibata A, Ishii K, Okazaki K, Oka K. [Developing Japanese version of the eHealth Literacy Scale (eHEALS)]. Nihon Koshu Eisei Zasshi 2011 May;58(5):361-371. [Medline: 21905612]

22. Paige SR, Krieger JL, Stellefson M, Alber JM. eHealth literacy in chronic disease patients: an item response theory analysis of the eHealth literacy scale (eHEALS). Patient Educ Couns 2017 Feb;100(2):320-326. [doi: 10.1016/j.pec.2016.09.008] [Medline: 27658660]

23. Paramio PG, Almagro BJ, Hernando G, Aguaded GJI. [Validation of the eHealth Literacy Scale (eHEALS) in Spanish University Students]. Rev Esp Salud Publica 2015;89(3):329-338 [FREE Full text] [doi: 10.4321/S1135-57272015000300010] [Medline: 26388346]

24. Stellefson M, Paige SR, Tennant B, Alber JM, Chaney BH, Chaney D, et al. Reliability and validity of the telephone-based ehealth literacy scale among older adults: cross-sectional survey. J Med Internet Res 2017 Oct 26;19(10):e362 [FREE Full text] [doi: 10.2196/jmir.8481] [Medline: 29074471]

25. Nguyen G, Gambashidze N, Ilyas SA, Pascu D. Validation of the safety attitudes questionnaire (short form 2006) in Italian in hospitals in the northeast of Italy. BMC Health Serv Res 2015 Jul 24;15:284 [FREE Full text] [doi: 10.1186/s12913-015-0951-8] [Medline: 26204957]

26. Richtering S, Morris R, Soh S, Barker A, Bampi F, Neubeck L, et al. Examination of an eHealth literacy scale and a health literacy scale in a population with moderate to high cardiovascular risk: Rasch analyses. PLoS One 2017;12(4):e0175372 [FREE Full text] [doi: 10.1371/journal.pone.0175372] [Medline: 28448497]

27. Koo M, Norman CD, Hsiao-Mei C. Psychometric evaluation of a Chinese version of the eHealth literacy scale (eHEALS) in school age children. Global J Health Educ 2012;15(1).

28. Wangdahl JM, Dahlberg K, Jaensson M, Nilsson U. Psychometric validation of Swedish and Arabic versions of two health literacy questionnaires, eHEALS and HLS-EU-Q16, for use in a Swedish context: a study protocol. BMJ Open 2019 Sep 17;9(9):e029668 [FREE Full text] [doi: 10.1136/bmjopen-2019-029668] [Medline: 31530602]

29. Terwee CB, Bot SDM, de Boer MR, van der Windt DA, Knol DL, Dekker J, et al. Quality criteria were proposed for measurement properties of health status questionnaires. J Clin Epidemiol 2007 Jan;60(1):34-42. [doi:

10.1016/j.jclinepi.2006.03.012] [Medline: 17161752]

30. Guillemin F, Bombardier C, Beaton D. Cross-cultural adaptation of health-related quality of life measures: literature review and proposed guidelines. J Clin Epidemiol 1993 Dec;46(12):1417-1432. [Medline: 8263569]

31. Mokkink LB, Terwee CB, Patrick DL, Alonso J, Stratford PW, Knol DL, et al. The COSMIN study reached international consensus on taxonomy, terminology, and definitions of measurement properties for health-related patient-reported outcomes. J Clin Epidemiol 2010 Jul;63(7):737-745. [doi: 10.1016/j.jclinepi.2010.02.006] [Medline: 20494804]

32. Valerio MA, Rodriguez N, Winkler P, Lopez J, Dennison M, Liang Y, et al. Comparing two sampling methods to engage hard-to-reach communities in research priority setting. BMC Med Res Methodol 2016 Oct 28;16(1):146 [FREE Full text] [doi: 10.1186/s12874-016-0242-z] [Medline: 27793191]

33. Wilson Van Voorhis CR, Morgan BL. Understanding power and rules of thumb for determining sample sizes. TQMP 2007 Sep 01;3(2):43-50. [doi: 10.20982/tqmp.03.2.p043] 
34. Sørensen K, Van den Broucke S, Pelikan JM, Fullam J, Doyle G, Slonska Z, et al. Measuring health literacy in populations: illuminating the design and development process of the European Health Literacy Survey Questionnaire (HLS-EU-Q). BMC Public Health 2013 Oct 10;13:948 [FREE Full text] [doi: 10.1186/1471-2458-13-948] [Medline: 24112855]

35. Wångdahl J, Mårtensson LJSM. Göteborg University. 2013. HLS-EU-Q16 Svensk version 2 URL: https://medicine.gu.se/ digitalAssets/1459/1459843 hls-eu-q16-svensk-version-2.pdf [accessed 2020-01-15]

36. Nielsen SS, Krasnik A. Poorer self-perceived health among migrants and ethnic minorities versus the majority population in Europe: a systematic review. Int J Public Health 2010 Oct;55(5):357-371. [doi: 10.1007/s00038-010-0145-4] [Medline: 20437193]

37. Benyamini Y. Why does self-rated health predict mortality? An update on current knowledge and a research agenda for psychologists. Psychol Health 2011 Nov;26(11):1407-1413. [doi: 10.1080/08870446.2011.621703] [Medline: 22111660]

38. Bujang M, Baharum N. A simplified guide to determination of sample size requirements for estimating the value of intraclass correlation coefficient: a review. Arch Orofacial Sci 2017;12(1). [doi: 10.1007/springerreference 205392]

39. De Vet H, Terwee C, Mokkink L. Measurement in Medicine: A Practical Guide. Cambridge: Cambridge University Press; 2011.

40. Palumbo R, Annarumma C, Adinolfi P, Musella M, Piscopo G. The Italian Health Literacy Project: insights from the assessment of health literacy skills in Italy. Health Pol 2016 Sep;120(9):1087-1094. [doi: 10.1016/j.healthpol.2016.08.007] [Medline: 27593949]

41. Paasche-Orlow MK, Parker RM, Gazmararian JA, Nielsen-Bohlman LT, Rudd RR. The prevalence of limited health literacy. J Gen Intern Med 2005 Feb;20(2):175-184 [FREE Full text] [doi: 10.1111/j.1525-1497.2005.40245.x] [Medline: 15836552]

42. Easton P, Entwistle VA, Williams B. Health in the 'hidden population' of people with low literacy. A systematic review of the literature. BMC Public Health 2010 Aug 05;10:459 [FREE Full text] [doi: 10.1186/1471-2458-10-459] [Medline: 20687946]

43. Levin-Zamir D, Baron-Epel OB, Cohen V, Elhayany A. The association of health literacy with health behavior, socioeconomic indicators, and self-assessed health from a national adult survey in israel. J Health Commun 2016;21(sup2):61-68. [doi: 10.1080/10810730.2016.1207115] [Medline: 27669363]

44. Almaleh R, Helmy Y, Farhat E, Hasan H, Abdelhafez A. Assessment of health literacy among outpatient clinics attendees at Ain Shams University Hospitals, Egypt: a cross-sectional study. Public Health 2017 Oct;151:137-145. [doi: 10.1016/j.puhe.2017.06.024] [Medline: 28800559]

45. Omariba DWR, $\mathrm{Ng}$ E. Health literacy and disability: differences between generations of Canadian immigrants. Int J Public Health 2015 Mar;60(3):389-397. [doi: 10.1007/s00038-014-0640-0] [Medline: 25549612]

46. Cronbach LJ. Coefficient alpha and the internal structure of tests. Psychometrika 1951;16(3):297-334. [doi: $10.1007 / \mathrm{bf02310555]}$

47. Pelikan J, Röthlin F, Ganahl K, Peer S. Measuring comprehensive health literacy in general populations-le HLS-EU instruments. 2014 Presented at: Second International Conference of Health Literacy and Health Promotion; 2014; Taipei.

48. McDowell I. Measuring Health: A Guide to Rating Scales and Questionnaires. NY: Oxford University Press; 2006.

49. de Vet HCW, Mokkink LB, Mosmuller DG, Terwee CB. Spearman-Brown prophecy formula and Cronbach's alpha: different faces of reliability and opportunities for new applications. J Clin Epidemiol 2017 May;85:45-49. [doi: 10.1016/i.jclinepi.2017.01.013] [Medline: 28342902]

50. Landis JR, Koch GG. The measurement of observer agreement for categorical data. Biometrics 1977 Mar;33(1):159-174. [Medline: $\underline{843571]}$

51. Drost EA. Validity and reliability in social science research. Educ Res Perspect 2011;38(1):105.

52. Rode N. Translation of measurement instruments and their reliability: an example of job-related affective well-being scale. Metodoloski Zvezki 2005;2(1):15. [doi: 10.1037/t01753-000]

53. Chung S, Nahm E. Testing reliability and validity of the eHealth Literacy Scale (eHEALS) for older adults recruited online. Comput Inform Nurs 2015 Apr;33(4):150-156. [doi: 10.1097/CIN.0000000000000146] [Medline: 25783223]

54. Chung S, Park BK, Nahm E. The Korean eHealth Literacy Scale (K-eHEALS): reliability and validity testing in younger adults recruited online. J Med Internet Res 2018 Apr 20;20(4):e138 [FREE Full text] [doi: 10.2196/jmir.8759] [Medline: $\underline{29678800]}$

55. Lin C, Broström A, Griffiths MD, Pakpour AH. Psychometric evaluation of the Persian eHealth Literacy Scale (eHEALS) among elder iranians with heart failure. Eval Health Prof 2019 Feb 11:163278719827997. [doi: 10.1177/0163278719827997] [Medline: $\underline{\text { 30744419] }}$

56. Mitsutake S, Shibata A, Ishii K, Okazaki K, Oka K. [Developing Japanese version of the eHealth Literacy Scale (eHEALS)]. Nihon Koshu Eisei Zasshi 2011 May;58(5):361-371. [Medline: 21905612]

57. Gazibara T, Cakic J, Cakic M, Pekmezovic T, Grgurevic A. eHealth and adolescents in Serbia: psychometric properties of eHeals questionnaire and contributing factors to better online health literacy. Health Promot Int 2018 May 25;34(4):770-778. [doi: 10.1093/heapro/day028] [Medline: 29800141]

58. Neter E, Brainin E, Baron-Opel O. The dimensionality of health literacy and eHealth literacy. Eur Health Psychol 2015;17(6):275-280. 
59. Sudbury-Riley L, FitzPatrick M, Schulz PJ. Exploring the measurement properties of the eHealth Literacy Scale (eHEALS) among baby boomers: a multinational test of measurement invariance. J Med Internet Res 2017 Feb 27;19(2):e53 [FREE Full text] [doi: 10.2196/jmir.5998] [Medline: 28242590]

60. Del Giudice P, Bravo G, Poletto M, De Odorico A, Conte A, Brunelli L, et al. Correlation between ehealth literacy and health literacy using the ehealth literacy scale and real-life experiences in the health sector as a proxy measure of functional health literacy: cross-sectional web-based survey. J Med Internet Res 2018 Oct 31;20(10):e281 [FREE Full text] [doi: 10.2196/jmir.9401] [Medline: 30381283]

\author{
Abbreviations \\ COSMIN: Consensus-Based Standards for the Selection of Health Measurement Instruments \\ eHealth: electronic health \\ eHEALS: eHealth Literacy Scale \\ HLS-EU-Q16: Health Literacy Survey European Questionnaire, 16-item \\ Sw-eHEALS: Swedish version of eHEALS
}

\author{
Edited by E Borycki, G Eysenbach; submitted 18.09.19; peer-reviewed by T Vreugdenhil, G Pravettoni, E Neter; comments to author \\ 13.11.19; revised version received 03.12.19; accepted 10.12.19; published 24.02.20 \\ Please cite as: \\ Wångdahl J, Jaensson M, Dahlberg K, Nilsson U \\ The Swedish Version of the Electronic Health Literacy Scale: Prospective Psychometric Evaluation Study Including Thresholds Levels \\ JMIR Mhealth Uhealth 2020;8(2):e16316 \\ URL: https://mhealth.jmir.org/2020/2/e16316 \\ doi: $10.2196 / 16316$ \\ PMID: 32130168
}

COJosefin Wångdahl, Maria Jaensson, Karuna Dahlberg, Ulrica Nilsson. Originally published in JMIR mHealth and uHealth (http://mhealth.jmir.org), 24.02.2020. This is an open-access article distributed under the terms of the Creative Commons Attribution License (https://creativecommons.org/licenses/by/4.0/), which permits unrestricted use, distribution, and reproduction in any medium, provided the original work, first published in JMIR mHealth and uHealth, is properly cited. The complete bibliographic information, a link to the original publication on http://mhealth.jmir.org/, as well as this copyright and license information must be included. 